\title{
Revisitando um clássico da interlocução do Serviço Social com a tradição marxista
}

\author{
Entrevista com Marilda Villela lamamoto* sobre os 33 anos \\ do livro Relações Sociais e Serviço Social no Brasil - \\ Esboço de uma interpretação histórico-metodológica \\ Isabel Cristina da Costa Cardoso \\ Mônica de Jesus Cesar**
}

1. O livro Relações sociais e Serviço Social no Brasil é o produto do seu trabalho em conjunto com Raul de Carvalho, vinculado ao projeto de Investigação do Centro Latinoamericano de Trabajo Social (Celats), que estabelece uma análise do Serviço Social como profissão no Brasil, no contexto histórico da sociedade capitalista entre 1930 e 1960. Poderia recapitular o período de sua inserção no Celats?

Nas décadas de 1970 e 1980, a presença do Brasil foi decisiva na renovação crítica do Serviço Social latino-americano, no lastro do "movimento de reconceituação" ${ }^{\prime \prime}$. Verifica-se, então, uma ampla articulação profissional no continente buscando um Serviço Social enraizado na América Latina, sob a liderança da Associación Latinoamericana de Trabajo Social

\footnotetext{
*Doutora em Ciências Sociais pela Pontifícia Universidade Católica de São Paulo (2001). Professora Titular (aposentada) da Escola de Serviço Social na Universidade Federal do Rio de Janeiro. Atualmente, é professora titular da Faculdade de Serviço Social da Universidade do Estado do Rio de Janeiro, atuando no Programa de Pós-graduação em Serviço Social.E-mail:<mviamamoto@uol.com.br>.

** Entrevista realizada por escrito, via e-mail, em julho de 2015, pela Prof ${ }^{\text {as. }}$ Dras. Isabel Cristina da Costa Cardoso e Mônica de Jesus Cesar, integrantes da Equipe Editorial da revista Em Pauta: teoria social e realidade contemporânea e docentes da Faculdade de Serviço Social (FSS/UERJ).

1 Podem ser citados, dentre outros, naquele período: Leila Lima Santos, Seno Cornely, Consuelo Quiroga, Jose Paulo Netto, Vicente de Paula Faleiros, Josefa Batista Lopes e Marieta Koike.
} 
(Alaets) e de seu organismo acadêmico, o Centro Latinoamericano de Trabajo Social (Celats). Eles desempenharam um papel exemplar na elaboração de um pensamento crítico no Serviço Social na América Latina vinculado aos interesses das maiorias, quando a pós-graduação e a pesquisa acadêmica davam seus primeiros passos nessa área. Contribuíram para o fortalecimento da organização acadêmico-profissional no marco continental, assim como na construção da fraternidade dos povos latino-americanos no embate com as ditaduras militares e o imperialismo.

Esse movimento político-cultural de renovação profissional ocorre no contexto da Guerra Fria, em um ciclo expansionista do capital que permite entender, inclusive, a presença do financiamento alemão por meio da Fundação Konrad Adenauer (FKA), no âmbito do Serviço Social no continente. Ela é indissociável da disputa pela hegemonia na América Latina por parte dos países "centrais". Um ciclo com tonalidade depressiva demarca o cenário mundial nos anos 1980, a que se alia a crise do Leste Europeu e a vitória do império norte-americano contra as forças democráticas, alimentando a expansão neoliberal.

Em 1974, a partir de um convênio de cooperação técnico-financeiro entre a Alaets e a FKA, intermediado pelo Instituto de Solidariedad Internacional (ISI) da Democracia Cristã Alemã, é criado o Celats. A entidade tem seus estatutos aprovados em 1975, em El Salvador, estabelecendo sua sede em Lima (Peru). Em 1976 foi reconhecida pelo governo peruano como organismo de cooperação técnica internacional.

Em 1978, eu ingresso no Celats como pesquisadora adjunta, a convite de Leila Lima Santos, então diretora da entidade. A proposta era de participar da elaboração e realização de um projeto de pesquisa sobre a história do Serviço Social na América Latina, sob a coordenação de Manuel Manrique Castro. Este projeto foi assumido como atividade principal da área de investigações do Celats para os anos de 1978 a 1979. O texto original desse projeto foi publicado na Revista do Celats $n^{\circ}$ 5, sob o título Hacia el estudio de la história del trabajo social en América Latina (CELATS, 1979, p. 53-73).

A revisão do acervo bibliográfico recolhido à época mostrava ser a literatura sobre a história do Serviço Social presidida ou por uma abordagem meramente descritiva da trajetória da profissão - a história reduzida a uma sequência evolutiva de acontecimentos -, ou por uma visão paralelista entre a história da profissão e a da sociedade, em que esta era tomada como mero "pano de fundo" para uma análise da "história interna" do Serviço Social. Verificou-se, ainda, um acentuado "latinoamericanismo" na leitura da história do Serviço Social em nível continental, traduzido na desconsideração das diferenças históricas dos países e gerando uma perspectiva generalista, com forte perda do potencial explicativo das especificidades nacionais.

Recusando tais caminhos, nosso projeto pautou-se numa abordagem orgânica das relações entre história da sociedade e da profissão, situada 


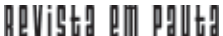

\} REVISITANDO UM CLÁSSICO - CARDOSO, I. C. C.; CESAR, M. J. \}

nas peculiares relações históricas entre Estado e sociedade civil nos países considerados: Brasil e Peru. Elegemos as relações entre as classes sociais e suas frações em suas relações com bloco do poder como o fulcro explicativo das demandas e da necessidade de institucionalização e desenvolvimento da profissão, considerando as particularidades nacionais. Como abordagem teórico-metodológica, buscamos inspiração na tradição marxista a partir de seus fundadores e de fontes originais. Era explícita, ainda, por parte dos pesquisadores, a intenção de romper os dilemas da primeira aproximação a essa tradição intelectual no Serviço Social latino-americano presidida por um "marxismo sem Marx", resultando numa "ética de esquerda e uma epistemologia de direita", tal qual denunciara Lukács (1963) em outra ocasião.

A pesquisa documental sobre a história do Serviço Social no Brasil foi por mim coordenada. Contou com a decisiva participação do economista e historiador Raul de Carvalho, que vem de uma família de doces e bravos lutadores. Sua mãe, Renée, é oficial da resistência francesa, e seu pai, Apolônio de Carvalho, um dos mais exemplares militantes da esquerda brasileira no marco das lutas internacionais socialistas, e certamente o seu mais terno figurante. Em 1935, ainda tenente, Apolônio de Carvalho lutou contra a ditadura de Vargas. Foi preso e expulso do exército. Em 1938, participou da Guerra Civil Espanhola, do lado da República e contra o fascismo franquista. Em 1942, tornou-se membro da resistência francesa, resistindo à invasão nazista. Na década de 1960, combateu a ditadura, tendo sido preso, torturado e trocado pelo embaixador alemão junto com trinta e nove presos políticos, passando a viver dois anos na Argélia e dois na França. Assinada a anistia, voltou ao Brasil e participou da fundação do Partido dos Trabalhadores. Recuperou sua patente de general do exército e faleceu em 2005.

Sabemos que a articulação do Serviço Social na América Latina, soldando uma unidade de diversidades nacionais, remonta ao ano de 1965, quando ocorre, em Porto Alegre, no Brasil, o I Seminário de Serviço Social face às mudanças sociais na América Latina. Este foi o primeiro marco público da busca por um Serviço Social latino-americano, reagindo à importação de parâmetros profissionais. Denuncia-se, assim, o capitalismo dependente e o imperialismo norte-americano, num ambiente político-cultural marcado pela vitória dos revolucionários de Sierra Maestra sobre Havana, das lutas estudantis de 1968, da abertura da Igreja Católica a partir do Concílio Ecumênico do Papa João XXII e da teologia da libertação. Este primeiro Seminário desdobrou-se em seis outros subsequentes, que assentam as bases para uma estruturação mais orgânica do Serviço Social no continente: em Montevidéu (1966), no Uruguai, em Concepción (1969), no Chile, em Cochabamba (1970), na Bolívia e, novamente, em Porto Alegre (1972), no Brasil.

A Alaets data de 1965 e foi criada no marco do V Congresso PanAmericano de Serviço Social da Organização dos Estados Americanos 
(OEA). No entanto, sua primeira refundação política ocorreu em Quito, no Equador, em 1971, sob a presidência do companheiro chileno Luís Araneda (gestão de 1971-1974) e movida pela busca de sua independência do Serviço Social norte-americano e da OEA, redirecionada aos dilemas latinoamericanos e à construção de um Serviço Social enraizado no continente.

A programação do Celats-Alaets, nas décadas de 1970 e 1980, contemplava basicamente três grandes áreas: a) investigação, voltada ao conhecimento dos setores populares: camponeses, operários, populacionais e indígenas; ao papel das políticas sociais públicas, em especial saúde e habitação; ao conhecimento da realidade institucional na qual opera o Serviço Social, suas associações profissionais e seu perfil profissional; e à história do Serviço Social na América Latina; b) capacitação continuada, permitindo uma reflexão sobre a atuação dos profissionais por meio de seminários, cursos a distância, além da organização da primeira pós-graduação em Serviço Social em nível continental, consubstanciada à Maestria Latinoamericana en Trabajo Social (MLATS), em convênio com a Universidad Autónoma de Honduras, sediada em Tegucigalpa; c) comunicação, com a publicação da série Livros-Celats, a Revista Acción Crítica e os Cuadernos Celats. Dentro desta programação, a minha inserção no Celats foi prioritariamente na área de investigação, na assessoria a projetos de capacitação continuada e outros eventos, tendo colaborado ainda no Mlats, minha primeira experiência na pós-graduação stricto sensu.

Do conjunto de ações acadêmicas e organizativas desenvolvidas pela entidade no período considerado, creio merecer destaque as seguintes atividades, por suas repercussões no Serviço Social brasileiro:

a) A pesquisa sobre a organização do Serviço Social na América Latina, desenvolvida pelo Celats, em 1977, sob a responsabilidade de Roberto Rodriguez e Walter Tesch ${ }^{2}$. As organizações sindicais e profissionais do Serviço Social viviam crises permanentes na concretização cotidiana de seu papel, uma clara debilidade associativa e uma mínima participação de seus membros. Remonta daí a necessidade de estabelecer contato com as associações e organizações nacionais, tendo em vista sua revitalização e fortalecimento, cabendo ao Celats a obtenção de fontes de financiamento para viabilizar este processo organizativo.

O Brasil dispunha, à época, de aproximadamente 16 mil assistentes sociais, dos quais cerca de 7 mil inscritos do Conselho Federal de Assistentes Sociais e respectivos Conselhos Regionais (CFAS-CRAS), criados em 1962 e distribuídos em 10 regionais. Hoje, somos cerca de 150 mil profissionais registrados no Conselho. Havia também 14 associações profissionais e 5 sindicatos localizados no Rio de Janeiro, Porto Alegre, Belo Horizonte e

2 Poblacional y gremial: dos investigaciones (CELATS, 1977). Foram investigadores regionais os assistentes sociais Eduardo Rodriguez, Norberto Alayon e Mirna López. 
Fortaleza, que formavam a organização gremial da categoria profissional. Depois de Argentina e México, o Brasil ocupava o terceiro lugar em número de cursos de Serviço Social, todos de nível superior, um diferencial ante aos demais países latino-americanos. A Associação Brasileira de Ensino em Serviço Social (Abess) congregava 37 dos 49 cursos de Serviço Social existentes à época e buscava a construção de um currículo mínimo para a formação acadêmica, aprovado pela entidade em 1979, na sua Convenção Nacional realizada em Natal (RN).

b) Em agosto de 1979 ocorre, no Rio de Janeiro, o I Encontro Nacional de Capacitação Continuada (IAMAMOTO; CARVALHO; LIMA, 1979), promovido pelo Celats em cooperação com o Instituto de Orientação às Cooperativas Habitacionais (Inocoop) e com a Pontifícia Universidade Católica do Rio de Janeiro (PUC-RJ). O evento reuniu representantes de faculdades, organismos representativos da categoria e entidades vinculadas ao trabalho de campo de 13 estados brasileiros: São Paulo, Minas Gerais, Goiás, Mato Grosso, Bahia, Paraíba, Espírito Santo, Sergipe, Rio Grande do Norte, Maranhão, Paraná, Santa Catarina e Rio de Janeiro. Este encontro encontrase na base da preparação do chamado "Congresso da Virada" (III CBAS), tendo privilegiado os seguintes temas: a) a relação entre prática profissional das instituições e contexto social; b) a dimensão política da prática profissional e c) a organização profissional.

O assistente social é reconhecido como trabalhador assalariado, funcionário de uma instituição, cuja ação condensa interesses de classe diferenciados. Afirma-se que a resposta institucional às necessidades dos trabalhadores depende da dinâmica de luta dos grupos e do poder de negociação e pressão que a classe trabalhadora possa dispor em determinadas conjunturas. O Serviço Social é compreendido enquanto parte da prática social coletiva de classes e grupos sociais com interesses contraditórios que conformam a sociedade, tendendo a ser cooptado por aqueles que são dominantes. Daí deriva a necessária dimensão política da pratica profissional: o assistente social opera políticas que traduzem intenções e interesses das classes fundamentais da sociedade e é por eles polarizado, afirmando-se a necessidade de opção em favor dos interesses de uma das classes fundamentais.

É constatado o precário nível organizativo da profissão e a necessidade de sua revitalização, numa conjuntura em que interesses imediatos da categoria se tornam convergentes aos dos amplos setores da população, incentivando a participação conjunta em lutas reivindicatórias. Vários depoimentos registram a participação direta dos assistentes sociais, a partir das instituições em que trabalham e dos organismos profissionais, nas lutas e mobilizações dos setores populares. Este tipo de prática fortalece a inte-

${ }^{3}$ Ver: Celats, 1979. 
gração das lutas sindicais da categoria a outras profissões, e destas com as lutas reivindicatórias dos setores populares.

Eu e Raul de Carvalho participamos do referido encontro como assessores, contribuindo na sistematização dos seus resultados. Foi a partir dessa primeira articulação que o Celats aportou recursos para o intercâmbio entre as entidades sindicais ou associações profissionais no país, o que desaguou numa presença organizada no III CBAS. As entidades representativas já se somavam às forças políticas de resistência, e a partir de então se unem para uma presença organizada no cenário profissional. Enfrentam o legalismo, a burocratização e o conservadorismo político dos Conselhos Regionais de Assistentes Sociais (CRAS) e do Conselho Federal (CFAS)

c) Em 1979, a partir de um grupo de cientistas sociais que o Celats congrega em suas atividades e sua assessoria, inaugura-se o debate sobre a política social no âmbito do Serviço Social latino-americano, no Simpósio de Playas, em Guayaquil (Equador) ${ }^{3}$. Esta abordagem permite situar o Serviço Social no âmbito das relações entre o Estado e a sociedade de classes, rompendo a análise isolada e endógena do exercício profissional. O Estado é tratado não apenas como um instrumento exclusivo de realização dos interesses da burguesia; ainda que seja um Estado burguês, ele expressa a condensação de forças sociais e, nesse sentido, as contradições das classes. Assim, a dominação é contraditória em dupla dimensão: porque expressa alianças de classes ou frações dominantes que não são similares, refletindo seus conflitos e pressões permanentes; e fundamentalmente porque, se o Estado exclui as chamadas classes dominadas, ele tem, em certa medida, que incorporar alguns de seus interesses, como afirmava o Prof. Lúcio Kowarick (USP) ao discorrer sobre o "pacto de dominação" (KOWARICK, 1979). Desta forma, as políticas sociais traduzem sempre uma tensão contraditória entre os imperativos da reprodução do capital por um lado e, por outro, as necessidades da reprodução da força de trabalho, para o que os gastos públicos são fundamentais. Esse caráter contraditório do Estado e das políticas social, cujo chão é a sociedade de classes, estende-se à análise da profissão.

A partir de 1980, passei a exercer funções de representação e assessoria junto ao Celats/Alaets, participando de iniciativas por eles promovidas: assessoria acadêmica ao Celats durante o curso sobre Elementos Teóricos de Política Social (São Paulo, 1980); participação na reunião de consulta, em nível latino-americano, sobre a pesquisa Industrialização, política social em habitação e trabalho social na América Latina (Lima, 1980); representação da Alaets na Comissão Organizadora do Encontro Prévio à Assembleia Geral Ordinária da Alaets (São Paulo, 1980); convidada e conferencista no Seminario Latino-Americano Trabajo Social en las últimas décadas: balance y perspectivas (Chaclacayo, Peru, 1982); conferencista no III Encuentro Centroamericano de Trabajo Social: México, Centroamérica y Caribe (Tegucigalpa, 1983). 
A partir de 1983, a minha relação com aquelas entidades latinoamericanas mudou de caráter: passei a participar, mediante indicação de nossos organismos representativos da categoria profissional (em especial, da Abess), como representante do Brasil em eventos como o Seminário de Capacitación de Instructores de Análisis de la Práctica (Lima, 1987) e na comissão latino-americana de reflexão e investigação sobre a prática profissional e estrutura curricular (Lima, jul. 1987). Participei, também, do projeto de pesquisa em nível latino-americano sobre El Proyecto pedagógico del Trabajo Social en América Latina e da Comissão Organizadora do Seminário Internacional, que tematizou aquela pesquisa, realizado na cidade de Natal (RN), em 1988.

Esse foi um momento de inflexão no direcionamento da vida acadêmica do Celats que, paulatinamente, foi se afastando de seu projeto de origem. Reduziu sua capacidade de atuação a alguns projetos no paíssede (Peru), prisioneiro dos dilemas de seu crescimento, da dependência da Fundação Konrad Adenaeur e da insuficiência de fontes de financiamento. Fragilizada com a perda de sua direção estratégica, a entidade passa a submeter-se aos rumos preconizados por organismos financiadores internacionais.

2. O trabalho de pesquisa foi levado a efeito durante o ano de 1978 como parte do projeto mais amplo sobre a história do Serviço Social na América Latina. Poderia nos contar como foi conduzido o processo de investigação e como ela transcorreu, considerando a dura repressão da Ditadura Militar no Brasil e também em outros países do continente?

A pesquisa sobre a história do Serviço Social no Brasil particularmente no eixo São Paulo-Rio de Janeiro foi realizada no período de um ano, consoante o contrato estabelecido por mim e por Raul de Carvalho com o Celats. Nós contamos com a colaboração de vários colegas e docentes. Saliento a generosa leitura crítica do projeto original da pesquisa feita pelo Prof. Dr. Octávio lanni (PUC-SP), que nos brindou com importantes sugestões e que, quando o trabalho ficou pronto, realizou nova leitura e aceitou o convite para redigir a quarta capa do livro. A prof. Dra. Maria Carmelita Yazbek (PUC-SP), à época presidente da então Abess e companheira de muitas lutas, redigiu a orelha do livro e também muito contribuiu para sua difusão no universo de assistentes sociais brasileiros.

A pesquisa contou, ainda, com o reforço de grupos de apoio formados por profissionais de Serviço Social do Rio de Janeiro e de São Paulo, onde se centralizou a consulta a arquivos e fontes documentais. Participaram desses grupos: Mariléa Venâncio Porfírio, Elizabeth Andrade Romeiro, Maria Lúcia Rezende Garcia, Dayse Gonçalves, Ana Maria de Vasconcelos e Maria Olímpia Quirino Costa, no Rio de Janeiro; Maria Carmelita Yazbek, Raquel 
Raichelis, Maria Rosângela Batistoni, Maria Beatriz da Costa Abramides, Sandra Márcia R. de Lins Albuquerque e Maria Célia Perez Fernandez Vilarinho, em São Paulo.

Ao longo do desenvolvimento da pesquisa foram realizadas cerca de duas reuniões de toda a equipe latino-americana para preparação de atividades e análise de resultados parciais. O intercâmbio da equipe ocorria via troca de materiais por correio - não havia comunicação on-line naquela época -, aproveitando ocasiões de eventos latino-americanos para a reuniões da coordenação.

Dentre as fontes documentais, além de revistas, publicações especializadas e trabalhos de conclusão de cursos (TCC) encontrados em acervos das bibliotecas das universidades consultadas, tivemos acesso ao rico acervo documental da primeira escola de Serviço Social do país, a Faculdade de Serviço Social da PUC-SP. Certamente o exíguo lapso temporal da pesquisa em um terreno praticamente virgem a ser desbravado, seja do ponto de vista da pesquisa histórica, seja do ponto de vista da orientação teórica que a presidiu, impôs uma série de limitações. Dentre elas, pode-se citar a área territorial de abrangência, o privilégio da influência católica nas origens do Serviço Social no país, a ausência de uma nítida demarcação da influência higienista nas origens do Serviço Social no país e os limites temporais impostos à sistematização de dados e ao tratamento analítico da vasta documentação coligida. Além disso, também a impossibilidade de, numa primeira aproximação, integrar a farta pesquisa documental com entrevistas no registro da memória dos sujeitos envolvidos, o que poderia atribuir visibilidade às polêmicas e resistências eventualmente presentes e não passíveis de registros escritos. Estas são algumas dentre muitas outras restrições decorrentes de um trabalho de pesquisa institucional num curto espaço de tempo, em uma área que, há 40 anos atrás, dispunha de muito pouca experiência e acúmulo na pesquisa histórica. Por tudo isto, o subtítulo do livro fala em esboço de uma interpretação histórico-sociológica aberta a desdobramentos e aprofundamentos.

Por outro lado, esta experiência nos alertou para a importância da guarda e manutenção dos arquivos documentais e fontes bibliográficas no registro coletivo da memória de iniciativas dos sujeitos e na reconstituição das origens e desenvolvimento da profissão no país. Resta o apelo às novas gerações de pesquisadores para que se debrucem sobre a pesquisa de fontes de época, inéditas, contribuindo para a reconstituição da memória do Serviço Social latino-americano.

O conjunto dos resultados daquele projeto de pesquisa mais amplo inclui outros resultados parciais, a saber: o trabalho de Alejandrino Maguina Larco (1979), Desarrollo capitalista y trabajo social, e de Manuel Manrique Castro (1982), De apostoles a agentes de cambio, editado no Brasil sob o título de História do Serviço Social na América Latina. Ressalto, ainda, o artigo de Raul de Carvalho (1980), Modernos agentes da justiça e da ca- 
ridade. Os resultados da pesquisa no Brasil foram publicados em 1982, no livro Relações sociais e Serviço Social no Brasil (IAMAMOTO, 1982a). Em 1985, quando já estava na terceira edição, foi vertido ao castelhano por Manuel Manrique Castro e publicado sob o título Relaciones sociales y trabajo social (CELATS, 1985). Recentemente, tive notícia de uma publicação da primeira parte dessa obra, em coedição entre Celats e Humanitas, datada de meados dos anos 1980, na Argentina, mas inteiramente desconhecida pelos autores. Somente em 1992 a minha dissertação de mestrado foi traduzida para o castelhano e publicada no seu formato original, o que completa a minha produção daquele período. Acrescento, ainda, outros artigos já publicados no Brasil, que compõem o livro Servicio Social e división del trabajo (IAMAMOTO, 1992a).

\section{O objetivo principal da investigação foi realizar uma análise} da profissão no Brasil, explicitando as articulações do desenvolvimento do Serviço Social e a dinâmica dos processos econômicos, sociais e políticos do país, à luz da teoria marxiana. Quais as dificuldades enfrentadas para introduzir, à época da primeira edição do livro, essa perspectiva crítica no Serviço Social brasileiro?

Comecemos pelo cenário em que ocorre a pesquisa no Brasil. O processo de renovação crítica do Serviço Social no Brasil é tributário de amplo movimento pela democratização da sociedade e do Estado no país, com forte presença das lutas operárias, que impulsionaram a crise da Ditadura Militar: a ditadura do grande capital, nos termos de lanni (1981). Foi no processo de ascensão dos movimentos políticos das classes trabalhadoras, das lutas em torno da defesa do Estado de Direito e da elaboração e aprovação da Carta Constitucional de 1988 que a categoria de assistentes sociais foi sendo socialmente questionada pela prática política de diferentes segmentos da sociedade civil e mostrou-se sensível aos clamores da história.

Durante o período ditatorial, muitos de nossos colegas foram capturados pelo ardil de transformar ciência em técnica social, subordinandose à razão instrumental seja pelo silêncio, seja pela conivência ativa com os poderes da ditadura. Buscavam o aperfeiçoamento técnico para a implementação de um conjunto de programas sociais compensatórios da repressão, do arrocho salarial e da desmobilização política das classes e grupos profissionais. Muitos se mostraram dóceis às orientações conservadoras e tecnocráticas a serviço do grande capital, ante à expansão do braço repressivo do Estado. Ali também foram sufocadas as primeiras iniciativas críticas que, durante o período desenvolvimentista, tiveram lugar nos trabalhos comunitários e de educação popular segundo a orientação de Paulo Freire.

Também houve lutas e resistências de parte dos assistentes sociais, muitos dos quais vitimados pela repressão do Estado, que ficaram sujeitos 
ao exílio ou à prisão arbitrária, à tortura, e foram condenados por tribunais militares guiados pela Lei de Segurança Nacional, expressão do terrorismo estatal. Data de 1979 a Lei de Anistia - que beneficia os torturados e os torturadores indiscriminadamente, e hoje clama-se por um amplo investimento das forças progressistas pela punição dos crimes contra a humanidade e pela abertura incondicional dos arquivos, cuja memória não foi ainda integralmente revelada.

Nas décadas de 1970 e 1980, diversos agentes exercem um papel decisivo na criação de forças de resistência à ditadura e ao processo de construção democrática, conforme acentua Alves (1984): a) a Igreja Católica, representada na Conferência Nacional dos Bispos do Brasil (CNBB), é forte aliada na defesa dos direitos humanos, na denúncia da violência do Estado e na defesa dos presos políticos. Basta lembrar a contribuição da Comissão de Justiça e Paz da Arquidiocese de São Paulo e as Comunidades Eclesiais de Base (Cebs) presentes nas periferias, nas favelas, junto aos migrantes, aos camponeses e assalariados rurais, aos detentos, negros, índios e trabalhadores urbanos; b) as associações de moradores de favelas ou associações comunitárias alimentam o fortalecimento do movimento popular no período de 1978 a 1984 (Governo João Figueiredo). Elas organizam as lutas por melhorias de condições de vida nos bairros e favelas, pressionando o poder público e fazendo campanhas mais amplas, como o Movimento Contra o Custo de Vida; c) a Ordem dos Advogados do Brasil (OAB) defende os presos políticos e denuncia prisões arbitrárias, tornando-se destacada porta-voz dos pontos de vista da oposição e questionamento da legitimidade da estrutura legal do Estado de Segurança Nacional e na defesa do Estado de Direto; d) a Associação Brasileira de Imprensa (ABI) combate a censura de imprensa, que também atinge o teatro, a literatura, o cinema, a música, os livros, as revistas e os jornais; e) a União Nacional dos Estudantes (UNE), reorganizada em 1977, realiza grandes manifestações e passeatas; f) o movimento sindical urbano e rural - este sob a liderança da Confederação dos Trabalhadores da Agricultura (Contag) - e suas 21 federações de trabalhadores rurais realizam grandes greves em 1978, 1979 e 1980. Os trabalhadores reagem aos mecanismos de controle dos sindicatos por parte do Ministério do Trabalho, defendem a revogação da política de controle salarial e o reconhecimento do direito às negociações coletivas, o direito de greve e a autonomia sindical. Reforçam, ainda, a luta por eleições diretas em todos os níveis de representação política, defendendo o retorno às formas democráticas de governo. A classe trabalhadora havia descoberto o seu poder com fortes vínculos entre as lideranças e as bases. A reforma política de 1979 faz emergir novos partidos políticos, entre os quais o Partido dos Trabalhadores (PT), em 1980, que passa a canalizar as reivindicações de diferentes movimentos populares, com novo tipo de organização.

Inaugurando uma abordagem crítico-analítica do Serviço Social, a partir da sua inserção na divisão social do trabalho à base de determinações 
teórico-metodológicas marxianas, o texto - o primeiro do gênero na literatura profissional brasileira e latino-americana - exigiu determinação política e enfrentamento do medo de retaliações pelas forças do poder instituído num contexto de abertura, mas com presença ostensiva das forças repressivas. Acresce-se a isto meu passado político que envolveu, a partir de 1971, um conjunto de arbitrariedades por parte da Ditadura Militar das quais fui vítima: prisão, tortura, aplicação do Decreto $n^{\circ} 477$, julgamento por tribunais militares, condenação e cumprimento de pena de seis meses, seguido de absolvição no Supremo Tribunal Militar ${ }^{4}$. No ano de 2002, após 31 anos, o Governo de Minas Gerais tomou a iniciativa de apurar os fatos e fazer justiça mediante a indenização dos torturados, assumindo a responsabilidade pública, que lhe é devida, junto às vítimas da tortura. Tive, assim com outros companheiros mineiros, o reconhecimento da tortura pelo Estado de Minas Gerais. Em minha carta pessoal à Comissão Estadual de Indenização às Vítimas de Tortura do Estado de Minas Gerais, afirmo:

Certamente as marcas e sofrimentos, que ficaram na vida de muitos, não podem ser eliminados ou ressarcidos. Elas desafiam o tempo, atualizam-se permanentemente, enraizados nas histórias de vida e nos corações de muitas famílias brasileiras. Entretanto o mais importante é que a denúncia dos atos violentos e arbitrários do passado ilumine o presente e seus desdobramentos futuros, na defesa e aprofundamento do regime e dos valores democráticos; e que os interesses da maioria se constituam, de fato, no desafio permanente da construção de uma nova nação brasileira, regida sob os princípios éticos da grande política.

\section{Considerando que o movimento de reconceituação não foi coeso e único ao nascer e nem em seu processo de crescimento, como vo- cê avalia a projeção da sua obra e a sua relação com esse movimento ${ }^{5}$}

O movimento de reconceituação do Serviço Social na América Latina teve lugar no período de 1965 a 1975, impulsionado pela intensificação das lutas sociais que se refratavam na universidade, nas Ciências Sociais, na Igreja e nos movimentos estudantis, dentre outros. Ele expressa um amplo questionamento da profissão (suas finalidades, fundamentos, compromissos éticos e políticos, procedimentos operativos e formação profissional) dotado de várias vertentes e com nítidas particularidades nacionais que reclamam pesquisa. No entanto, sua unidade assentava-se na busca pela construção de um Serviço Social latino-americano: na recusa da im-

\footnotetext{
${ }^{4}$ Recentemente prestei largo depoimento à Comissão Municipal da Verdade de Juiz de Fora (MG). Os resultados do trabalho de pesquisa dessa CV foram publicados em Memórias da repressão pela própria Comissão Municipal da Verdade de Juiz de Fora (2015), disponível para acesso on line.

${ }^{5}$ Tive oportunidade de tratar sistematicamente do tema da reconceituação no texto base da conferência exigida para Concurso Público de Professor Titular da UFRJ, em1992, publicado em lamamoto (1992).
} 
portação de teorias e métodos alheios à nossa história, na afirmação do compromisso com as lutas dos "oprimidos" pela "transformação social" e no propósito de atribuir um caráter científico às atividades profissionais. Denunciava-se a pretensa neutralidade político-ideológica, a restrição dos efeitos de suas atividades aprisionadas em microespaços sociais e a debilidade teórica no universo profissional. Os assistentes sociais, então, assumem o desafio de contribuir na organização, capacitação e conscientização dos diversos segmentos trabalhadores e "marginalizados" na região.

De base teórica e metodológica eclética, esse movimento foi inicialmente polarizado pelas teorias desenvolvimentistas. Em seus desdobramentos, especialmente a partir de 1971, este movimento representou as primeiras aproximações do Serviço Social à tradição marxista, haurida em manuais de divulgação do marxismo-leninismo, na vulgata soviética, em textos maoístas, no estruturalismo francês de Althusser, além de outras influências de menor porte. Registra-se, entretanto, a ausência de uma aproximação rigorosa aos textos de Marx.

Esse período coincide com a Ditadura Militar no Brasil, fazendo com que o debate aqui assumisse outras tonalidades e recebesse distintas influências, especialmente do vetor modernizador e tecnocrático, combinado com extratos da filosofia aristotélico-tomista no âmbito dos valores e princípios éticos. O Brasil dispunha, nesse período, de um polo de resistência a esta vertente modernizadora, liderada pela Escola de Serviço Social da Universidade Católica de Minas Gerais (ESS/UCMG), integrado aos rumos do movimento de reconceituação latino-americano, tal como se expressou nos países de língua espanhola.

A oportunidade de uma interlocução mais próxima com a produção profissional "de ponta" da reconceituação no continente ocorreu ainda em 1971. Mediante bolsa (obtida através do trabalho de conclusão de curso intitulado Emergência e formação de líderes num trabalho comunitário - VILLELA; PACHECO, 1971), fui selecionada para participar do Seminário Latinoamericano de Profesionales en Trabajo Social, realizado em Ambato (Equador). Tratava-se de um evento restrito, reunindo profissionais representativos de vários países do continente, promovido pelo Instituto de Solidariedade Internacional (ISI), vinculado à Fundação Konrad Adenauer.

Nítidas linhas divisórias do movimento de reconceituação adquirem visibilidade, entre os "iniciadores" (Herman Kruse, Ezequiel AnderEgg, Natálio Kisnerman, Seno Cornely e outros) e os novos protagonistas do debate profissional latino-americano (Vicente de P. Faleiros, Leila Lima Santos, Juan Mojica Martinez, Boris Lima, Roberto Rodriguez, Tereza Quiróz e outros). A unidade desses novos interlocutores, apesar das suas diferenças internas, é a busca por fundamentos para a análise profissional no campo dos "marxismos".

Ainda nesse período, tive a oportunidade de travar contato com a versão "oficial" das interpretações sobre a profissão através do III Congresso 
Interamericano de Bem-Estar Social, promovido à mesma época, em Quito, pela Conferência Interamericana de Bem-Estar Social. Aí está contextualizada minha aproximação ao cenário latino-americano do Serviço Social. É com a bagagem crítica dessa vivência profissional, e na interlocução com a mesma, que se insere a pesquisa sobre a história do Serviço Social no Brasil na perspectiva da superação das elaborações típicas do movimento de reconceituação latino-americano nos países de língua espanhola, especialmente no Cone Sul. Além disso, dos limites da experiência acadêmica mineira de Belo Horizonte, bem como de um explícito confronto com a perspectiva modernizadora assumida majoritariamente por aquele movimento no país sob a liderança do Cbciss.

Eu concluí o curso de graduação em fevereiro de 1971, na Faculdade de Serviço Social da Universidade Federal de Juiz de Fora, e imediatamente iniciei as atividades no campo da docência em Serviço Social, em Belo Horizonte, na então Universidade Católica de Minas Gerais. Simultaneamente, inseri-me no mercado profissional mediante concurso público, tornando-me assistente social do Instituto Nacional de Previdência Social. Ingressei na carreira docente na condição de recém-formada. Encontrei, pois, na Escola de Serviço Social da Universidade Católica de Minas Gerais, um grupo docente ativo, de explícita composição interdisciplinar, preocupado com a renovação profissional e integrado ao debate latino-americano do movimento de reconceituação. Ali participei da construção de uma proposta globalizadora da revisão da profissão e da formação profissional, traduzida, hoje, no conhecido "Método Belo Horizonte".

Essa experiência é considerada por Netto (1991) como a formulação inicial e mais abrangente da vertente profissional no pós-1964, que ele qualifica como "intenção de ruptura" com as marcas conservadoras e modernizantes do Serviço Social brasileiro. As propostas e análises aí formuladas - pouco difundidas no país, à época, dados os constrangimentos político-institucionais - ganham ampla visibilidade no meio profissional latino-americano. Embora no Brasil aquela experiência só tenha sido parcialmente publicada em Santos (1982), já em 1973 o seu projeto de reestruturação da formação profissional do Serviço Social foi publicitado por uma das casas editoras de maior influência profissional na América Latina na época, a Ecro, de Buenos Aires, nas seguintes coletâneas: Compendio sobre la metodología del trabajo social (QUIROGA et al. 1973a) e Compendio sobre la reestructuración de la carrera de trabajo social (QUIROGA at al.. 1973b).

Encontra-se no chamado "Método Belo Horizonte" um conjunto de críticas centrais ao tradicionalismo profissional: à sua pseudoneutralidade teórico-prática, ao caráter segmentado na abordagem dos fenômenos sociais, à visão dicotômica das relações sujeito-objeto (traduzidas no dualismo homem-meio) e à importação de modelos teórico-operativos desconectados das particularidades históricas latino-americanas. Acresce-se a essa teia de 
críticas, ainda, a visão - subjacente e tácita - normalizadora da sociedade, redundando em objetivos profissionais eivados pelos propósitos de atenuar disfunções sociais, desadaptações e desvios comportamentais, tão caros às interpretações de cunho funcionalista da dinâmica social. ${ }^{6}$

Não se pode omitir que, sendo a experiência da UCMG exemplar de uma das tendências presentes na polêmica profissional de uma época, ela traz em si as limitações teórico-metodológicas e as ilusões características de uma parcela da vanguarda profissional progressista naquele momento. Dentre estas, podem ser destacadas: a atualização de marcas messiânicas ainda que travestidas de uma roupagem politizada de "esquerda" - no trato dos objetivos-fins profissionais; "a transformação do homem e da sociedade" mediada pelos processos de capacitação, conscientização e organização, e inspirados na perspectiva de Paulo Freire, a pedagogia do oprimido. Decorre daí uma visão polarizadora da sociedade, dividida entre opressores e oprimidos, alimentada por ingredientes teóricos extraídos do arsenal da vulgarização marxista. Um outro traço característico da referida proposta é a tensão presente entre os propósitos de uma análise de inspiração marxista no campo teórico-metodológico e as fortes marcas epistemologistas que a informam.

De fato, percebe-se uma completa ausência, na análise, do trabalho como fonte da produção do ser social, fundante na reflexão marxista. Poderíamos afirmar que, do ponto de vista teórico-metodológico, a proposta em discussão exemplifica tipicamente o que Quiroga (1989) qualifica como "invasão às ocultas" do positivismo no marxismo. O traço eclético que preside os fundamentos teóricos que sustentam o "Método Belo Horizonte" explica aquela "invasão": o estruturalismo althusseriano, o marxismo difundido a partir da II Internacional, haurido em manuais de "marxismo-leninismo" na sua versão "oficial"; a inspiração maoísta presente na análise das relações: teoria e prática, redundando num empirismo inconteste da máxima "a prática como fonte de teoria", tal qual ali é trabaIhada. Soma-se a essas observações a formalização dos momentos metodológicos, resultante de uma exemplar sistematização da prática, erigida como fonte de revisão e elaboração de teorias.

Tais comentários críticos, aqui sinteticamente expressos, não embaçam a importância da experiência antes assinalada, enquanto abertura de horizontes ideoculturais no processo de renovação do Serviço Social e na construção de uma proposta para a prática profissional institucionalizada no mercado de trabalho, contrapondo-se à avalanche de críticas conservadoras ao movimento de reconceituação, que acentuam unilateralmente o seu caráter de mera denúncia do passado profissional.

\footnotetext{
${ }^{6}$ Para uma análise global da experiência do grupo de Belo Horizonte, ver: A prática como fonte de teoria (1971); Uma proposta de reestruturação da formação profissional (QUIROGA, C. et al. 1973b); Teoria, prática, Serviço Sociale análise histórica da orientação metodológica da Escola de Serviço Social da Universidade Católica de Minas Gerais (LIMA, 1982). Ver, ainda: Lima (1977), Netto (1991), Barbosa (1989) e Rodrigues da Silva (1991).
} 
Na proposta de reestruturação do ensino teórico-prático, merece menção a análise da Universidade Brasileira nos moldes do acordo MECUsaid aí presente. Busca resgatar a possibilidade de condução do processo curricular a partir da recuperação do relativo espaço de autonomia existente no âmbito decisório interno às unidades de ensino. Afirma-se uma concepção globalizadora de currículo, que articula o ensino teórico-prático à pesquisa e à prática, operacionalizado nas "unidades de ensino e aprendizagem". Por meio das "equipes de prática", articuladas em torno de problemáticas básicas de investigação e intervenção profissional e apoiada em uma orientação interdisciplinar, verificam-se inéditos avanços ante a uma questão até hoje não resolvida a contento no campo da formação de graduação no país: a relação entre formação teórica e exercício profissional.

Em que pesem as diferenças nacionais, o debate nos países de língua espanhola do Cone Sul era fortemente marcado por uma perspectiva crítico-dialética que passava pelos condutos da prática político-partidária, em que inquietudes eram transferidas da militância para a profissão. Estabelecia-se frequentemente uma relação de identidade entre militância e profissão, deixando de lado suas diferenças e impedindo, assim, a análise de suas mútuas relações. Tais caminhos condicionam também os meios teóricos pelos quais se deu a aproximação ao marxismo: manuais de divulgação do "marxismo oficial", autores descobertos na militância política (Lênin, Trotsky, Mao, Guevara) cujas produções eram seletivamente apropriadas numa ótica utilitária em função de exigências prático-imediatas.

Difunde-se, ainda, uma clara dissociação entre o chamado "materialismo histórico e o materialismo dialético". A categoria trabalho, ontologicamente determinante na obra de Marx, está inteiramente ausente ao passo em que se disseminam os "metodologismos" e os "vieses epistemológicos". O resultado desse ecletismo teórico, com fortes traços positivistas, é um claro empobrecimento do potencial da análise marxiana, essa desconhecida. Verificase uma tensão entre propósitos políticos anunciados e os recursos teórico-metodológicos acionados para iluminá-los. Originase daí o duplo dilema presente no exercício profissional: fatalismo e messianismo, voluntarismo e determinismo, cativos de uma análise da "prática profissional" esvaziada de historicidade.

No Brasil, a ditadura propiciou o aprofundamento da expansão monopolista com significativas alterações no processo produtivo, na reorganização do Estado, com irradiações no conjunto dos aparelhos de hegemonia da sociedade civil (em especial a universidade). Tais condições históricas tornaram possível a gestação de um novo perfil profissional ainda no período ditatorial: consolida-se um mercado de trabalho efetivamente nacional para os assistentes sociais, cresce o contingente profissional, realizase a efetiva inserção da formação nos quadros universitários, sujeita às exigências de ensino, pesquisa e extensão. Por fim, instala-se a pós-graduação stricto sensu, nutrindo a produção científica, o diálogo acadêmico com áreas afins, o mercado editorial e a renovação dos quadros docentes. 
Esta maturação acadêmica - ainda em tempos sombrios, que lançaram profundas amarras sobre a sociedade civil - irá florescer no período da crise da ditadura. Aí o Serviço Social vive um descompasso: ao mesmo tempo em que dispõe de condições materiais para dar o salto necessário, visando responder ao avanço das lutas pelos direitos sociais e políticos, carecia de massa crítica para embasar uma autorrenovação nesses rumos. Este descompasso propiciou um reencontro do Serviço Social brasileiro com as inquietudes profissionais e políticas do movimento de reconceituação, mas já não era possível sua mera reiteração.

A sociedade brasileira, bem como a profissão, havia amadurecido historicamente. Simplesmente repor aquelas inquietações significaria potencializar os seus equívocos. Dessa maneira, para a dinamização da análise crítica do Serviço Social não restou outra alternativa senão dar um mergulho na pesquisa histórica, aliado a uma crítica teórica rigorosa do ideário profissional (ainda inconclusa). Em outros termos, um esforço de articulação entre a história do país, a crítica do conhecimento e a profissão, que passa a presidir o debate brasileiro no âmbito da tradição marxista. É nesse percurso que se insere o esforço da pesquisa sistematizada no livro Relações sociais e Serviço Social no Brasil (IAMAMOTO, 1982a), numa relação de continuidade e ruptura com o movimento de reconceituação. A continuidade se expressa na busca por manter vivo o espírito que cultiva a crítica. Ela se dirige tanto ao conservadorismo profissional quanto à vulgarização marxista, no resgate do legado marxiano para inspirar a análise da sociedade e da profissão.

Já a ruptura foi construída no processo mesmo de aprofundamento das premissas e propósitos da reconceituação. Seu próprio desenvolvimento, adensado pelas inéditas condições histórico-profissionais presentes na nossa sociedade, criou as possibilidades para a ultrapassagem da reconceituação: a sua superação na busca de novos parâmetros profissionais. É nessas veredas coletivas que situo a minha produção acadêmica.

O livro, que é meu e de Raul, tem sido objeto de controvérsias: ora é incorporado por muitos dos trabalhos que o sucederam, ora é alvo de críticas e polêmicas, como já registrei em outra ocasião (IAMAMOTO, 2007), o que denota a persistente vitalidade dessa produção. A ampla difusão de nosso trabalho hoje em sua $45^{\underline{a}}$ edição é tributária da luta teórica e profissional que, durante duas décadas, vem atribuindo um perfil crítico e hegemônico ao Serviço Social brasileiro. Luta essa que é organicamente articulada pelas nossas entidades representativas no campo da formação e do exercício profissional.

No campo do ensino graduado, a definição do currículo mínimo proposto pela Associação Brasileira de Ensino em Serviço Social, em 1979, e aprovado pelo Conselho Federal de Educação em 1982 (Parecer n. 412/ 82), previa disciplinas obrigatórias referentes à teoria, história e metodologia do Serviço Social, o que certamente favoreceu a difusão deste livro. Também 
contribuiu o debate que travei com a categoria profissional e com estudantes em fóruns dos mais diversos e em diferentes estados do país. Tal difusão fez com que a perspectiva de análise da profissão elaborada se tornasse domínio público, passando a ser incorporada à linguagem corrente de parcelas muito significativas dos assistentes sociais do país.

A partir dos 18 anos de seu lançamento, o livro Relações sociais e Serviço Social no Brasil (IAMAMOTO, 1982a) tem sido alvo de especiais homenagens, como a promovida pelo Conselho Regional de Serviço Social (Cress - 7aㅡ Região). Ela ocorreu durante os eventos comemorativos do Dia do Assistente Social, em 15 de maio de 2000, e contou com a generosa alocução do Prof. Dr. José Paulo Netto. Também durante a Oficina Nacional da Associação Brasileira de Ensino e Pesquisa em Serviço Social (Abepss), realizada em Niterói, em junho de 2002, a viva e criteriosa análise da Prof. Dra. Maria Rosângela Batistoni, então vice-presidente da Abepss, salientou elos do conteúdo do livro com o debate contemporâneo do Serviço Social no país. Os autores foram surpreendidos e agraciados com uma inédita iniciativa no Serviço Social brasileiro: a publicação de uma "fortuna crítica" comemorativa dos vinte anos de lançamento do livro.

Registro, ainda, a delicada comemoração organizada pela Escola de Serviço Social da UFRJ aos 21 anos do lançamento do livro, motivo de fortes emoções, acompanhada de um debate retrospectivo sobre o livro e exposição da memória da pesquisa. Por ocasião do $7^{\circ}$ Seminário Anual de Serviço Social, promovido pela Ed. Cortez, o conjunto de minha produção e, em particular, o livro em coautoria com Raul de Carvalho, foi motivo de especial e emocionante homenagem anotada no edital da Revista Serviço Social e Sociedade no 120 (2014, P. 606-607). A Asociación Latinoamericana de Enseñanza e Investigación en Trabajo Social (Alaeits) indicou, por duas vezes subsequentes, meu trabalho à candidatura da maior premiação do Serviço Social mundial ao nível da formação acadêmico-profissional - o Prêmio Katherine A. Kendall, da International Association of Schools of Social Work (IASSW) -, o que foi para mim motivo de agradável surpresa.

\section{Como o livro Relações sociais e Serviço Social no Brasil se in- sere em sua trajetória pessoal de interlocução com a tradição marxista?}

Minha aproximação inicial à tradição marxista foi movida pela necessidade de conhecimento para orientar a ação política, e ocorreu pelo viés da militância política voltada para a política de massas (e não a luta armada). Tiveram ressonância naquele período a experiência da revolução cultural chinesa (a obra de Mao Tsé-Tung, em particular o trecho de seu livro vermelho sobre a prática, a teoria e outros textos selecionados), a saga de Ernesto Guevara na América Latina, as lutas contra a segregação racial nos EEUU, capitaneadas por Martin Luther King, as leituras sobre o estrutu- 
ralismo de Althusser e seus seguidores em moda na academia (Politzer, Marta Harneck) e o marxismo soviético voltado ao debate sobe a ciência.

Soma-se a este universo eclético a teologia da libertação, a proposta de alfabetização e educação popular de Paulo Freire, amplamente assumida pelo Movimento de Educação de Base (MEB). Estudos sobre a chamada "realidade brasileira" foram apoiados na produção de historiadores (Caio Prado Junior, Nelson Werneck Sodré, Alberto Passos Guimarães, entre outros) e na produção da escola sociológica da USP, que abrangia temas como industrialização, empresariado, sindicalismo, questão racial, desenvolvimento e teoria da dependência.

A experiência profissional e política mostraram-me com nitidez a necessidade do aprofundamento histórico-teórico numa dupla direção: de um lado, no campo do pensamento social, bem como seus desdobramentos nas ciências sociais e na teoria social calcada na tradição marxista; de outro, a exigência de ampliar conhecimentos sobre as relações Estado/ sociedade no Brasil como condição fundante para decifrar - rompidos os mitos das interpretações dominantes nos anos 1960 - as tendências do movimento da expansão capitalista no país.

Preocupava-me, basicamente, os rumos e as fraturas da revolução burguesa no Brasil, na qual o "mundo agrário" constituía uma variávelchave a ser deslindada. Tais preocupações levaram-me ao encontro da "sociologia e da sociedade agrárias". E eis que ingressei como aluna regularmente matriculada, em 1976, no Curso de Mestrado em Sociologia Rural da Escola Superior de Agricultura "Luiz de Queiróz", da Universidade de São Paulo (Campus de Piracicaba).

A formação acadêmica, que tive o privilégio de experimentar no mestrado, foi decisiva para o meu desenvolvimento intelectual e para os rumos analíticos que, a partir de então, passei a imprimir às análises sobre o Serviço Social. Ressalto apenas dois "pilares" daquela qualificação. O primeiro expressou-se na chance que me foi oferecida de entrar em contato direto com os "clássicos". De uma parte, por meio dos cursos ministrados pelo Prof. Dr. José Albertino R. Rodrigues (Evolução do pensamento social e Teoria sociológica). Li os autores mais representativos na formulação do pensamento social - dos utopistas renascentistas (Morus, Bacon, Campanella), passando pelos reformistas religiosos e sociais (Lutero, Munzer, Calvino), aos teóricos políticos (Hobbes, Locke, Montesquieu, Rousseau), aos enciclopedistas e aos socialistas "utópicos" e "científicos". Também frequentei sociólogos como Comte, Durkheim, Weber, Pareto e Parsons - além, naturalmente, de Marx. O debate sobre a sociedade brasileira centrado sobre a questão agrária, sob a orientação do Prof. Dr. Oriowaldo Queda, permitiume acumular elementos para responder às indagações que me levaram ao curso de Sociologia Rural.

O segundo pilar refere-se à participação sistemática em grupos de estudos orientados pelo Prof. Dr. José de Souza Martins, no Depar- 


\section{Revigta 미 paltg}

\} REVISITANDO UM CLÁSSICO - CARDOSO, I. C. C.; CESAR, M. J. \}

tamento de Ciências Sociais da Faculdade de Filosofia, Letras e Ciências Humanas da Universidade de São Paulo, onde realizei a leitura das obras econômicas fundamentais de Marx: O capital (1985), O capital, capitulo VI Inédito (1974), Elementos fundamentais para a crítica da economia política (1857-1858) (1978) e Teorias sobre a mais-valia (1980).

Por meio da leitura de autores clássicos, na constituição do pensamento social e na formalização da sociologia, foi-me possível ampliar a visão sobre o processo de construção do conhecimento como um processo acumulativo histórico-social, apreendendo o seu caráter historicamente determinado e percebendo concretamente que seus limites e possibilidades permanecem enraizados nos limites e possibilidades do desenvolvimento de uma época. Assim, os vínculos entre conhecimento e história tornaramse, para mim, patentes. Outra conquista diz respeito à ruptura com os dogmatismos político-ideológicos de diversas ordens na apreciação das teorias, típicos da formação por meio da prática política. A maneira como foi conduzida a análise do pensamento social - partindo da reconstituição do progresso técnico-científico da época, de suas bases econômicas, dos marcos políticos fundamentais, aliados à biografia dos autores e à apresentação global de suas produções, de seus críticos e comentaristas - trouxe, em contrapartida, o reconhecimento da importância do pluralismo no debate teórico e a necessidade de conhecimento interior das propostas dos interlocutores para o embate com o pensamento deles. Além disso, de buscar uma apropriação que fosse o mais fiel possível à lógica que preside a construção de suas investigações. Em outros termos: iniciei-me no trabalho da produção e da crítica teórica.

Tal aprendizado foi influenciado, ainda, pelas leituras sistemáticas efetuadas, no decorrer de sete anos, das obras fundamentais de Marx para a explicação da sociedade capitalista, tendo por referência o caso "clássico" inglês. Como já fiz menção, tais estudos, realizados sob a forma de seminários, com elevado padrão acadêmico, foram organizados em torno de uma preocupação central: "a questão teórico-metodológica". Em outras palavras, sobre o que Lukács (1974, p. 15) denominou "marxismo ortodoxo", que não significa a adesão acrítica aos resultados da pesquisa de Marx ou a exegese de um texto sagrado; a ortodoxia remete ao método, que só pode ser aprofundado no sentido de seus fundadores.

Tive, portanto, o privilégio de realizar um rigoroso estudo teóricometodológico da produção marxiana movido pela preocupação de ir além da apreensão conceitual para entender como o texto é construído, como pensa o autor, como se expressa, subjacente ao texto, a lógica e a história que dão sentido à sua argumentação e à sua própria produção. Destarte, o método foi localizado no interior da construção teórica, expurgando quaisquer formalismos nesse campo. Buscava-se detectá-lo no interior da exposição das conclusões obtidas no campo da explicação histórico-sistemática, das investigações empíricas e do diálogo com os seus interlocutores 
mais significativos. Tendo iniciado esse programa de estudos com $O$ capital - a obra mais acabada construída dentro dos padrões estritos do "método de exposição" - acompanhada do Capítulo VI, Inédito, do Livro I e seguida dos materiais preparatórios de O capital - os Gründrisse (1980a) - e do Teorias sobre a Mais-valia (Tomo IV de O capital 1980b), foi-me possível, assim, estabelecer contato com a sistemática de investigação do autor, com o processo de construção da crítica da economia política. Encontrei um "outro" Marx, que me era até então desconhecido: um incansável pesquisador, um crítico rigoroso voltado para a superação da produção acumulada e um teórico monumental. Nesse processo, também entrei necessariamente em intimidade com o trabalho no campo da abstração, como um recurso heurístico fundamental para a análise das formas sociais, como assinala o próprio Marx no prefácio à 1a edição de O capital (MARX, 1985).

A partir desse conjunto de leituras, foram lançados os alicerces para a continuidade dos estudos, cujo seguimento dei por conta própria, tanto no campo dos clássicos da Sociologia, quanto no amplo campo da tradição marxista, recorrendo a Weber, Durkheim e à Escola Francesa; também a Engels, Lênin e Luxemburgo. Frequentei, ainda, autores contemporâneos: Lukács, Lefebvre, Marcuse, Schaff, Séve, G. Markus, Heller, Gramsci, Kosik, entre outros.

No tocante à "questão agrária", foi-me possível visitar uma extensa bibliografia sobre os clássicos e a literatura brasileira contemporânea, com especial ênfase no estudo das relações sociais de produção presentes no campo brasileiro, estreitamente conectadas à expansão monopolista, em um país de passado escravista e colonial com uma tradição política marcada pelas particularidades de uma "via prussiana" de desenvolvimento (LÊNIN, 1980). Essa tematização, desenvolvida diferencialmente por Coutinho (1980), nos termos da "revolução pelo alto", e por lanni (1984), na análise da "contrarrevolução burguesa permanente", facilitou meu interesse pelos dilemas de interpretação da recriação da pequena produção nas suas diferentes formas e pelas formas de assalariamento presentes na agricultura.

Dentro desse leque de preocupações, participei de grupos de estudos, na década de 1970, sobre movimentos sociais rurais e violência no campo, na Associação dos Sociólogos de São Paulo; de eventos científicos sobre os caminhos da agricultura brasileira e de pesquisas na Fundação Getúlio Vargas (SP) sobre o desenvolvimento agrícola comparado (Brasil, México, Peru). Como se pode inferir, essas temáticas exigiram um mergulho no processo histórico da expansão capitalista na sociedade brasileira com o intuito de agarrar suas particularidades.

Foi com esta bagagem teórica, política e profissional que enfrentei o desafio de pensar o Serviço Social no processo de reprodução das relações sociais, construindo uma análise sem referências anteriores nas quais pudesse me apoiar, mas com muitas provocações intelectuais oriundas do material empírico coligido a ser decifrado e processado pela análise teórica. Eu me 


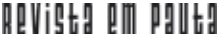

\} REVISITANDO UM CLÁSSICO - CARDOSO, I. C. C.; CESAR, M. J. \}

desfiava: se o propósito da obra de Marx é pensar as leis que regem o desenvolvimento e as transformações da sociedade capitalista, ela só tem sentido se contribuir para elucidar os processos sociais que a constituem e as criações e atividades humanas dela decorrentes no marco da divisão social e técnica do trabalho, entre as quais a profissão de Serviço Social. Mas há um longo caminho a percorrer...

Finalizando, gostaria de agradecer ao Comitê Editorial da Revista Em Pauta pela oportunidade desta entrevista, que recebi como uma honra e um reconhecimento à minha produção acadêmica. 


\section{Referências}

ALVES, M. H. Estado e oposição no Brasil (1964-1984). Petrópolis: Vozes. 1984. BARBOSA, M. M. Objetivos profissionais e objetivos institucionais na trajetória do Serviço Social: Belo Horizonte, 1960-1984. São Paulo: PUC. 1989. CASTRO, M. M. De apostoles a agentes de cambio. El trabajo social en la historia latinoamericana. Peru: Celats. 1982.

1984.

. História do Serviço Social na América Latina. São Paulo: Cortez.

CARVALHO, R. de. Modernos agentes da justiça e da caridade. Serviço Social e Sociedade, São Paulo: Cortez, n. 1. 1980.

CELATS. Poblacional y gremial: dos investigaciones Celats. Acción Crítica, Lima: Celats/Alaets, n. 2, jul. 1977.

. Política social: algunos problemas levantados en el Simposio de Playas. Acción Crítica, Lima: Celats/Alaets, n. 5. 1979.

COUTINHO, C. N. A democracia como valor universal. São Paulo: Ciências Humanas. 1980.

IAMAMOTO, M. V. Proposta de interpretação histórico-metodológica. In: IAMAMOTO, M. V; CARVALHO, R. Relações sociais e Serviço Social no Brasil. Esboço de uma interpretação histórico-sociológica. São Paulo: Cortez; Celats. 1982a.

IAMAMOTO, M. V.. Legitimidade e crise do Serviço Social. Ensaio de interpretação sociológica. Piracicaba: ESALQ; USP. 1982b.

. Servicio Social e división del trabajo. Un análisis crítico de sus fundamentos. São Paulo: Cortez. 1992a.

. Serviço Social na contemporaneidade: trabalho e formação profissional. São Paulo: Cortez. 1992b.

. Renovação e conservadorismo no Serviço Social. Ensaios críticos. São Paulo: Cortez. 1992c.

. O debate contemporâneo da reconceituação do Serviço Social: ampliação e aprofundamento do marxismo. In: Serviço Social na contemporaneidade: trabalho e formação profissional. São Paulo: Cortez. 1998.

. Serviço Social em tempo de capital fetiche. Capital financeiro, trabalho e questão social. São Paulo: Cortez. 2007.

IAMAMOTO, M. V.; CARVALHO, R.; LIMA, L. Encuentro Nacional de Capacitación. Acción Crítica, Lima: Celats; Alaets, n. 6, set. 1979. 
IAMAMOTO, M. V.; CARVALHO, R. Relaciones sociales y Trabajo Social. Lima: Celats, 1985.

- Relações sociais e Serviço Social no Brasil. Esboço de uma interpretação histórico-sociológica. São Paulo: Cortez; Celats. 1982.

IANNI, O. A ditadura do grande capital. Rio de Janeiro: Civilização Brasileira. 1981.

. O ciclo da revolução burguesa. Petrópolis: Vozes. 1984.

KOWARICK, L. Proceso del desarollo del Estado em América Latina y políticas sociales. Acción Crítica, Lima: Celats; Alaets, n. 5, abr. 1979.

LARCO, A. M. Desarrollo capitalista y trabajo social. Peru: Celats. 1979.

LENIN, V. I. O programa agrário da social democracia na primeira revolução russa de 1905-1907.São Paulo: Livraria de Ciências Humanas, 1980

LUKÁCS, G. La teoria du roman. Genebra: Gonthier. 1963.

. História e consciência de classe. Porto: Publicações Escorpião. 1974.

MANRIQUE, M. C.; IAMAMOTO, M. V. Hacia el estudio de la história del trabajo social en América Latina. Acción Crítica, Lima: Celats, n. 5. 1979. MARX, K. O capital. Crítica da economia política. São Paulo: Nova Cultural. 1985.

. El capital. Libro I. Buenos Aires: Siglo XXI. 1973.

Elementos fundamentales para la crítica de la economía política (Gründrisse). 1857-1858. México: Siglo XXI. 1980a.

MARX, K. Teorias sobre la plus-valia. México: Fondo de Cultura Económica. 1980b.

NETTO, J. P. Autocracia burguesa e Serviço Social. (Doutorado em Serviço Social) São Paulo: PUC. 1991.

QUIROGA, C. Uma invasão às ocultas: reduções positivistas no marxismo e suas manifestações no ensino de Serviço Social. São Paulo: Cortez. 1989.

QUIROGA, C. et al. Compendio sobre la metodología del trabajo social. Buenos Aires: Ecro. 1973a.

. Compendio sobre la reestructuración de la carrera de trabajo social. Buenos Aires: Ecro. 1973b.

RODRIGUES DA SILVA, L. M. Aproximação do Serviço Social à tradição marxista: caminhos e descaminhos. Tese (Doutorado) - PUC, São Paulo. 1991. SANTOS, L. L. Textos de Serviço Social. São Paulo: Cortez. 1982.

VILLELA, M. S.; PACHECO, M. E. Emergência e formação de líderes num trabalho comunitário. Trabalho de Conclusão de curso - UFJF, Juiz de Fora. 1971. 